\title{
MEMANFAATKAN LIMBAH PLASTIK MENJADI PAVING BLOCK
}

\author{
TEGUH $^{1}$, HARTATI ${ }^{2}$, Steven ANTHONY ${ }^{3}$, Bonita HIRZA ${ }^{4}$, dan Yetty HASTIANA ${ }^{5}$ \\ 1,2,3Universitas Terbuka, 4,5 Universitas Muhammadiyah Palembang \\ Email: teguhz@ecampus.ut.ac.id
}

\begin{abstract}
Plastic waste becomes one of the sources of environmental pollution problems. Landfill in the final landfill in Palembang, will be a serious problem if it is not sought solution. This community service is in the form of counseling and processing training of plastic waste into paving block given to the partners of the community in the location where the garbage disposal. The provision of counseling and training is expected to be the process of utilizing science and technology in the utilization of plastic waste so it is economically beneficial for the community because it has a high selling value. The implementation phase of this activity in the form of 1) establishment of partnership by determining the community, 2) fulfillment of production equipment, 3) counseling on the innovation of entrepreneurship and marketing of products, 4) training of paving block making. The result of this activity is that partners can make paving blocks from plastic waste and have entrepreneurial innovation and product marketing.
\end{abstract}

Keywords: plastic waste, paving block, pollution problems

\begin{abstract}
ABSTRAK
Sampah plastik menjadi salah satu sumber masalah pencemaran lingkungan. Timbulan sampah di tempat pembuangan sampah akhir di Palembang, akan menjadi masalah serius apabila tidak dicari cara penyelesaiannya. Kegiatan pengabdian kepada masyarakat ini berbentuk penyuluhan dan pelatihan mengolah limbah plastik menjadi paving block yang diberikan kepada mitra kelompok masyarakat di lokasi tempat pembuangan akhir sampah. Pemberian penyuluhan dan pelatihan ini diharapkan menjadi proses pemanfaatan IImu Pengetahuan dan Teknologi dalam pemanfaatan limbah plastik sehingga bermanfaat secara ekonomis bagi masyarakat karena mempunyai nilai jual tinggi.Tahap pelaksanaan pada kegiatan ini berupa 1) pembentukan kemitraan dengan menentukan kelompok masyarakat, 2) pemenuhan alat produksi, 3) penyuluhan tentang inovasi kewirausahaan dan pemasaran produk, 4) pelatihan pembuatan paving block. Hasil dari kegiatan ini adalah mitra bisa membuat paving block dari limbah plastik dan memiliki inovasi kewirausahaan dan pemasaran produk.
\end{abstract}

Kata kunci: limbah plastik, paving block, pencemaran lingkungan 


\section{PENDAHULUAN}

\section{Dasar Pemikiran dan Analisis}

Hampir setiap orang pasti tidak terlepas dari yang namanya bahan plastik dalam aktivitasnya sehari-hari. Plastik telah menjadi komponen penting dalam kehidupan modern saat ini (pictame) dan peranannya telah menggantikan kayu dan logam mengingat kelebihan yang dimilikinya seperti: ringan dan kuat, tahan terhadap korosi, transparan dan mudah diwarnai, serta sifat insulasinya yang cukup baik (koran Indonesia).

Sifat-sifat bahan plastik inilah yang membuatnya sulit tergantikan dengan bahan lainnya untuk berbagai keperluan, khususnya dalam kehidupan sehari-hari mulai dari kemasan makanan, alat-alat rumah tangga, mainan anak, elektronik sampai dengan komponen otomotif. Peningkatan penggunaan bahan plastik ini mengakibatkan peningkatan produksi sampah plastik dari tahun ke tahun (Alamendah,2009). Sebagai gambaran konsumsi plastik di Indonesia mencapai $10 \mathrm{~kg}$ perkapita pertahun, sehingga dapat diprediksikan sebesar itulah sampah plastik yang dihasilkan.

Seperti telah kita ketahui plastik sangat sulit terurai, membutuhkan waktu bertahun-tahun untuk penguraian bahan plastik di tanah, hal ini akan menimbulkan permasalahan tersendiri dalam penanganannya. Peranan para pengumpul sampah (pemulung) dalam mengurangi timbunan sampah plastik perlu mendapat apresiasi walaupun tidak bisa menghilangkan 100\% sampah plastik yang ada. Bagaimana upaya yang bisa dilakukan agar meningkatkan kesadaran masyarakat, minimal masyarakat memilah sampah yang bisa dibawa ke bank sampah atau ke tempat industri daur ulang agar tidak bertimbun ditempat pembuangan akhir sampah atau masuk ke perairan merupakan hal yag harus dilakukan dengan serius.

Salah satu usaha yang dapat dilakukan dan bernilai ekonomi tinggi adalah mendaur ulang sampah plastik menjadi paving block untuk keperluan penataan lingkungan perumahan dan perkotaan.

\section{Tujuan dan Manfaat}

Tujuan yang ingin dicapai dalam kegiatan abdimas ini adalah: memberikan pelatihan membuat paving block dari bahan limbah plastik. Jika tujuan tersebut tercapai diharapkan hasil kegiatan dapat bermanfaat untuk meningkatkan penghasilan keluarga masyarakat di sekitar TPA, dan bagi dosen Universitas Terbuka akan terjalin komunikasi yang efektif dan produktif untuk peningkatan peran serta kalangan kampus dalam pemberdayaan masyarakat luas.

\section{TINJAUAN TEORITIS}

Sampah dalam ilmu kesehatan lingkungan sebenarnya hanya sebagian dari benda atau hal-hal yang dipandang tidak digunakan, tidak dipakai, tidak disenangi, atau harus dibuang, sedemikian rupa sehingga tidak sampai mengganggu kelangsungan hidup (researchgate). Dari segi ini dapat disimpulkan bahwa yang dimaksud dengan sampah ialah sebagian dari sesuatu yang tidak dipakai, tidak disenangi atau sesuatu yang harus dibuang, yang umumnya berasal dari kegiatan yang dilakukan oleh manusia (termasuk kegiatan industri), tetapi yang bukan biologis (karena human waste tidak termasuk didalamnya) dan umumnya bersifat padat (Wahyono \& Sudarno, 2012).

Sampah dapat dibagi menjadi sampah padat, sampah cair dan sampah dalam bentuk gas (fume, smoke). Sampah padat dapat dibagi menjadi:

\section{Berdasarkan zat kimia yang terkandung didalamnya}

a. Sampah anorganik misalnya : logam-logam, pecahan gelas, dan plastik

b. Sampah organik misalnya : sisa makanan, sisa pembungkus dan sebagainya

2. Berdasarkan dapat tidaknya dibakar

a. Mudah terbakar misalnya : kertas, plastik, kain, kayu

b. Tidak mudah terbakar misalnya : kaleng, besi, gelas 
Diseminasi: Jurnal Pengabdian kepada Masyarakat

Volume: 2 No: 1 Tahun 2020

E-ISSN: 2655-2221 P-ISSN: 2655-2175

Hal: $1-4$

3. Berdasarkan dapat tidaknya membusuk

a. Mudah membusuk misalnya : sisa makanan, potongan daging

b. Sukar membusuk misalnya : plastik, kaleng, kaca (Wahyono dan Sudarno, 2012)

\section{HASIL PELAKSANAAN KEGIATAN}

\section{Hasil Kegiatan}

Kegiatan pemanfaatan limbah plastik ini menghasilkan Paving Block (Conblock) yang bisa digunakan untuk menutupi permukaan tanah. Untuk membuat satu buah paving block diperlukan $\pm 3 \mathrm{~kg}$ limbah plastik. Paving Block yang dihasilkan berbentuk seperti gambar berikut:

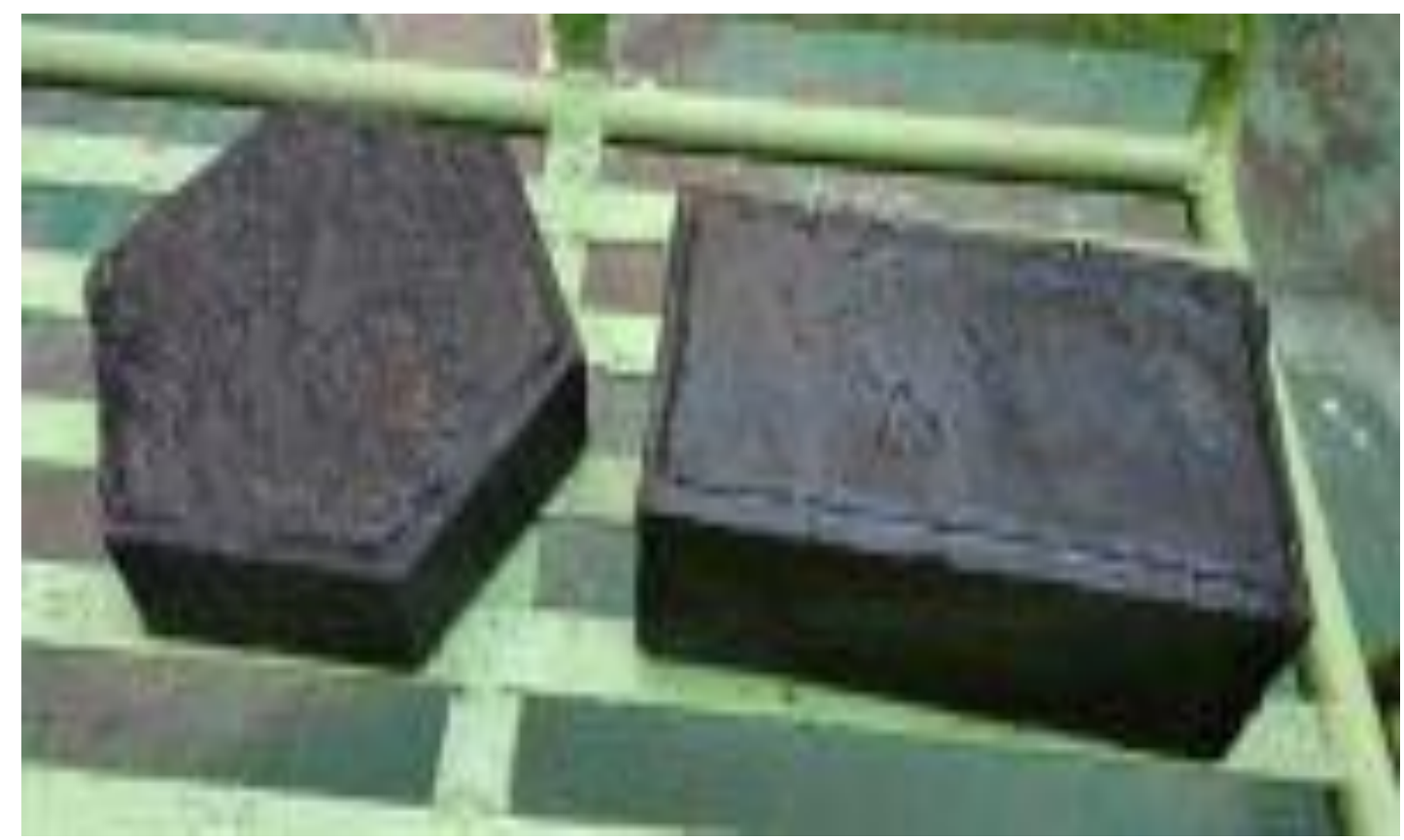

2. Pembahasan

Menggunakan paving block sebagai penutup permukaan akan membantu menjaga persediaan air di dalam tanah, karena daya serapnya yang baik. Paving block ini bisa menghindari munculnya genangan air di permukaan, sehingga sangat berguna untuk dipakai didaerah yang rawan banjir dan padat penduduknya (Asiacon, 2018).

Paving Balock yang dibuat dari limbah plastik memiliki beberapa kelebihan dibandingkan Paving Block yang biasa diperjual belikan di toko bahan bangunan, kelebihan Paving Block plastik ini adalah bobotnya yang lebih ringan, daya tahan terhadap beban, tidak akan pecah untuk selamanya, dan harganya relatif bisa lebih murah mengingat paving block ini dibuat dari limbah plastik yang selama ini tidak diambil oleh pemulung plastik.

KESIMPULAN

Masyarakat perlu diberi pelatihan untuk membuat paving block dari limbah plastik untuk memanfaatkan sampah plastik, dan mengurangi sampah plastik yang masuk ke Tempat Pembuangan Akhir (TPA) sampah 


\section{SARAN DAN REKOMENDASI}

Pejabat penentu kebijakan diharapkan bisa memfasilitasi masyarakat ditingkat kelurahan untuk mengikuti pelatihan membuat paving block, dan memanfaatkan paving block yang dibuat untuk menutupi permukaan tanah di sepanjang trotoar atau dilingkungan perumahan.

\section{DAFTAR PUSTAKA}

Alamendah, 2009. Dampak Plastik Terhadap Lingkungan. https://alamendah.org/2009/07/23/dampakplastik-terhadap-lingkungan/. Diakses 8 Januari 2019.

Koranindonesia.id https://koranindonesia.id/60-sampah-plastik-jadi-tumpukan-abadi-di-tpa/ diakses $25 / 08 / 2019$

Pengolahan Limbah Plastik Menjadi Produk Kreatif Sebagai Peningkatan Ekonomi Masyarakat Pesisir. https://www.Researchgate.Net/Publication/ 326044239 Pengolahan_Limbah_Plastik_Menjadi_Produk_Kreatif Sebagai Peningkatan Ekonomi Masyarakat_Pesisir. Diakses 8 januari 2019.

Polusi Plastik. https://id.wikipedia.org/wiki/Polusi_. Diakses 8 Januari 2019.

Wahyono, E. H. dan Sudarno.N. 2012. Pengelolaan Sampah Plastik: Aneka Kerajinan dari Sampah Plastik. Bogor: Yapeka 